\title{
Spatial variation in allometric growth of invasive lionfish has management implications
}

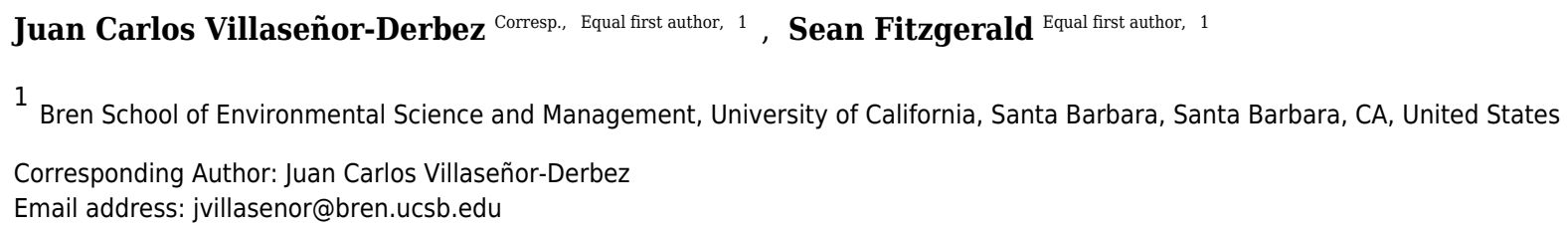

Lionfish (Pterois volitans / miles) are an invasive species in the Western Atlantic and the Caribbean. Improving management of invasive lionfish populations requires accurate total biomass estimates, which depend on accurate estimates of allometric growth, but sedentary species like lionfish often exhibit high levels of spatial variation in life history characteristics. We reviewed 17 published length-weight relationships for lionfish taken throughout their invasive range and found regional differences that led to significant misestimates when calculating weight from length observations. The spatial pattern we observed is consistent with findings from other studies focused on genetics or length-atage. Here, the use of Itextit ex situ\} parameter values resulted in total biomass estimates between $76.2 \%$ and $140 \%$ of true observed biomass, and up to a threefold under- or overestimation of total weight for an individual organism. These findings can have implications for management in terms of predicting effects on local ecosystems, evaluating the effectiveness of removal programs, or estimating biomass available for harvest. 


\title{
Spatial variation in allometric growth of invasive lionfish has management implications
}

\author{
Juan Carlos Villaseñor-Derbez ${ }^{1}$ and Sean Fitzgerald ${ }^{1}$ \\ ${ }^{1}$ Bren School of Environmental Science and Management, University of California, \\ Santa Barbara, Santa Barbara, CA, United States \\ Corresponding author: \\ Juan Carlos Villaseñor-Derbez ${ }^{1}$ \\ Email address: juancarlos@ucsb.edu
}

\begin{abstract}
Lionfish (Pterois volitans / miles) are an invasive species in the Western Atlantic and the Caribbean. Improving management of invasive lionfish populations requires accurate total biomass estimates, which depend on accurate estimates of allometric growth, but sedentary species like lionfish often exhibit high levels of spatial variation in life history characteristics. We reviewed 17 published length-weight relationships for lionfish taken throughout their invasive range and found regional differences that led to significant misestimates when calculating weight from length observations. The spatial pattern we observed is consistent with findings from other studies focused on genetics or length-at-age. Here, the use of ex situ parameter values resulted in total biomass estimates between $76.2 \%$ and $140 \%$ of true observed biomass, and up to a threefold under- or overestimation of total weight for an individual organism. These findings can have implications for management in terms of predicting effects on local ecosystems, evaluating the effectiveness of removal programs, or estimating biomass available for harvest.
\end{abstract}

\section{INTRODUCTION}

Lionfish (Pterois volitans/miles complex) are an invasive species in the Western Atlantic Ocean and Caribbean Sea, likely introduced through release of aquarium-kept organisms (Betancur-R et al., 2011). Lionfish are the first invasive marine vertebrates established along these coasts (Schofield, 2009, 2010; Sabido-Itza et al., 2016), and they have established invasive populations in coral reefs, estuaries, mangroves, hard-bottomed areas, and mesophotic reefs (Barbour et al., 2010; Jud et al., 2011; Muñoz et al., 2011; Claydon et al., 2012; Andradi-Brown et al., 2017; Gress et al., 2017). Their presence has been labeled as a "major marine invasion" because they threaten local biodiversity, spread rapidly, and are difficult to manage (Hixon et al., 2016).

A substantial amount of research describes lionfish impacts throughout their invaded range. A metaanalysis by Peake et al. (2018) showed that invasive lionfish prey on at least 167 different species across the tropical and temperate Western Atlantic. Their feeding behavior and high consumption rates can reduce recruitment and population sizes of native reef-fish species, and can further endanger reef fish (Green et al., 2012; Rocha et al., 2015, but see Hackerott et al. 2017 for a counterexample). For example, field experiments showed that lionfish establishment in the Bahamas led to reduced recruitment of native fishes by nearly $80 \%$ over a five-week period (Albins and Hixon, 2008), and prey fish biomass declined by $65 \%$ over two years as lionfish biomass increased along Bahamian coral reefs (Green et al., 2012). However, trophic impacts of lionfish can be minimized if their local biomass is controlled by culling (Arias-Gonzalez et al., 2011).

Governments and non-profit organizations have sought to reduce lionfish densities through removal programs and by incentivizing its consumption (Chin et al., 2016). In some cases, these have shown to significantly reduce - but not quite eliminate - lionfish abundances at local scales (de Leon et al., 2013; Sandel et al., 2015). Complete eradication of lionfish through fishing is unlikely because of their rapid recovery rates and ongoing recruitment to shallow-water areas from persistent populations in mesophotic 
ecosystems (Barbour et al., 2011; Andradi-Brown et al., 2017). However, promoting lionfish consumption might create a level of demand capable of incentivizing a stable fishery while controlling shallow-water populations, thus creating alternative livelihoods and avoiding further negative effects to local biota.

The feasibility of establishing fisheries through lionfish removal programs has been extensively evaluated through field observations and empirical modeling (Barbour et al., 2011; Morris et al., 2011; de Leon et al., 2013; Johnston and Purkis, 2015; Sandel et al., 2015; Usseglio et al., 2017). Determining the feasibility of such initiatives requires modeling the change in biomass in response to changes in fishing mortality (i.e., culling). A common way to model this is via length-structured population models, where fish lengths are converted to weight to calculate total biomass (Barbour et al., 2011; Côté et al., 2014; Andradi-Brown et al., 2017). The allometric length-weight relationship is thus an essential component of these models, but this relationship can vary across regions as a response to biotic and abiotic conditions (Johnson and Swenarton, 2016).

Outcomes of previous studies suggest lionfish are likely to exhibit spatial heterogeneity in the lengthweight relationship for both behavioral and biological reasons. Important life history characteristics such as growth or natural mortality rates are often spatially variable for fish that exhibit sedentary behavior (Gunderson et al., 2008; Hutchinson, 2008; Wilson et al., 2012; Guan et al., 2013), and in fact, high levels of site fidelity and small home ranges are two primary reasons why culling programs are effective in reducing local adult lionfish populations (Fishelson, 1997; Kochzius and Blohm, 2005; Jud and Layman, 2012; Côté et al., 2014). Genetic analysis of lionfish also identified two genetically distinct invasive subpopulations between the Western Atlantic and the Caribbean, suggesting the existence of spatially explicit biological differences between populations as well (Betancur-R et al., 2011). Site-specific studies that calculate the length-weight relationship of lionfish report variable estimates, and these differences may be increasingly important when estimating the potential effectiveness of lionfish culling programs (Barbour et al., 2011; Morris et al., 2011; Côté et al., 2014; Johnston and Purkis, 2015). However, the influence of using ex situ parameters when estimating the length-weight relationship remains unexplored.

Our objective was to quantify the magnitude of error caused by using ex situ parameter values when estimating lionfish weight from length observations. In this study, we calculated and reported the first length-weight relationship for lionfish in the central Mexican Caribbean using previously collected in situ observations ( $\mathrm{n}=109$; Villaseñor-Derbez and Herrera-Pérez (2014)). We then estimated lionfish weight in this area using previously published length-weight relationships for lionfish populations from ten locations across the Western Atlantic, Gulf of Mexico, and Caribbean. By comparing these weight estimates to our in situ length-weight observations, we showed that using ex situ parameter values resulted in up to a threefold under- or overestimation of lionfish weight and estimated of total biomass ranged between $76 \%$ and $140 \%$ of observed total biomass.

\section{METHODS}

We reviewed 12 published studies and obtained 17 length-weight relationships for the Western Atlantic (n $=2)$, Gulf of Mexico $(n=7)$, and Caribbean ( $n=8$, Table 1, Fig 1). Study sites included North Carolina, the Northern and Southern Gulf of Mexico, the Southern Mexican Caribbean, the Bahamas, Little Cayman, Jamaica, Bonaire, Puerto Rico, and Costa Rica (Barbour et al., 2011; Darling et al., 2011; de Leon et al., 2013; Fogg et al., 2013; Dahl and Patterson, 2014; Edwards et al., 2014; Toledo-Hernández, 2014; Sandel et al., 2015; Aguilar-Perera and Quijano-Puerto, 2016; Sabido-Itza et al., 2016; Sabido-Itzá et al., 2016; Chin et al., 2016). We have access only to the summarized information published in these studies - not the raw data authors used to make length-weight calculations. We collected information on sex differentiation, location, length and depth ranges, and sampling methods from each study when available. Only two studies reported sex-specific length-weight parameters (Aguilar-Perera and Quijano-Puerto, 2016; Fogg et al., 2013), so we assumed data were reported for both sexes combined in all other studies. Reviewed studies presented information for organisms ranging from $25-475 \mathrm{~mm}$ in Total Length $(T L)$ and were obtained at depths between $0.5 \mathrm{~m}$ and $57 \mathrm{~m}$. Four studies explicitly stated that their organisms were sampled with pole spears (Dahl and Patterson, 2014; Aguilar-Perera and Quijano-Puerto, 2016; Chin et al., 2016; Sabido-Itzá et al., 2016), and six studies mentioned that some of their organisms were obtained with pole spears (or other type of harpoon) but also hand-held nets or fish traps (Barbour et al., 2011; Fogg et al., 2013; Edwards et al., 2014; Toledo-Hernández, 2014; Sandel et al., 2015; Sabido-Itza et al., 2016). Two studies did not specify how organisms were sampled (Darling et al., 2011; de Leon et al., 2013).

We also used data from 109 lionfish sampled by Villaseñor-Derbez and Herrera-Pérez (2014), who 
used hand nets and numbered bottles to collect Total Length (TL; mm) and Total Weight (TW; g) for organisms from 10 sampling sites along the central Mexican Caribbean coast in the Summer of 2010 (Supplementary Table 1). Sampling locations included wall and carpet reefs at depths between $5.7 \mathrm{~m}$ and $38.1 \mathrm{~m}$. The use of hand nets prevented any weight loss due to bleeding and allowed better representation of small sizes by avoiding gear selectivity. Organisms were euthanized via pithing.

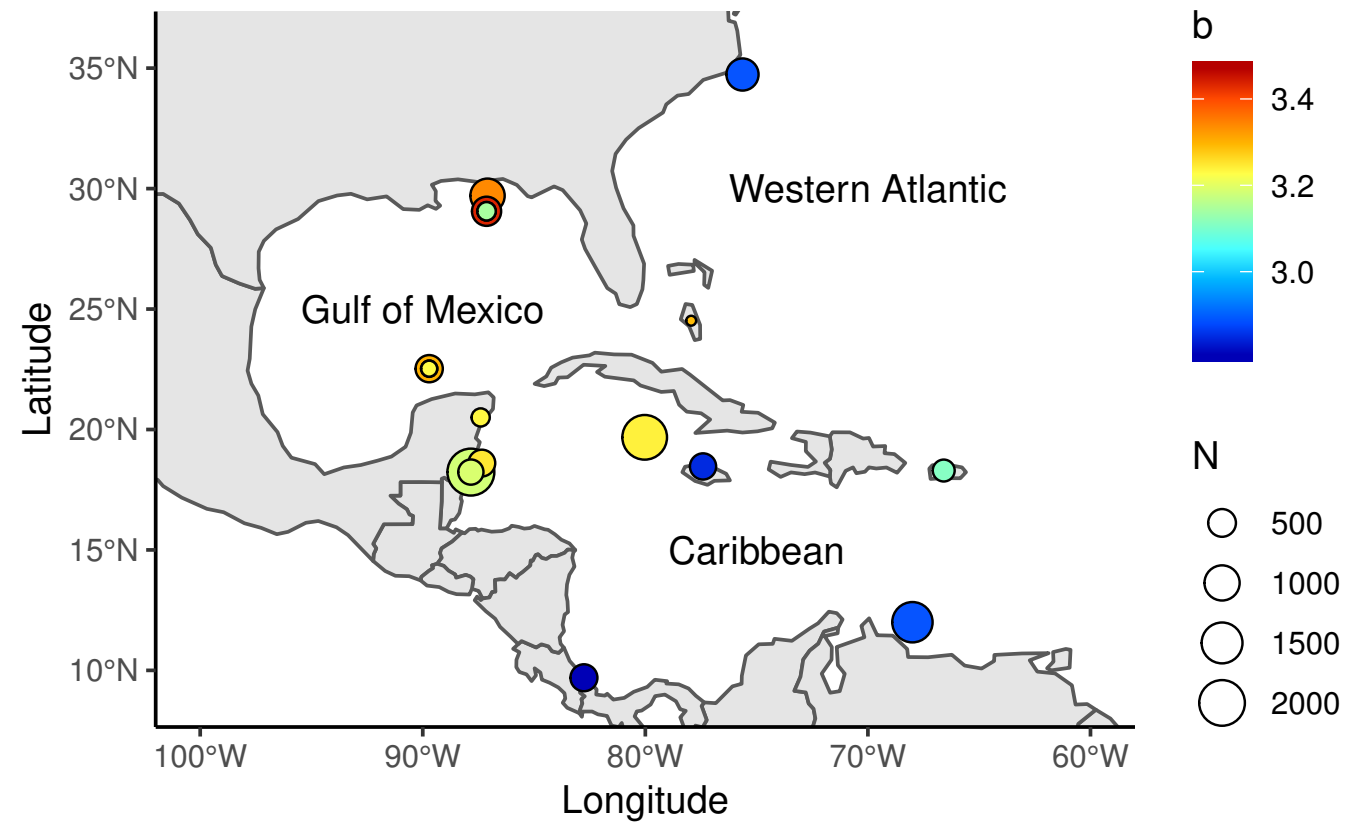

Figure 1. Locations where allometric growth parameters of lionfish (Pterois spp) have been reported. Circle sizes indicate sample size from each study, colors indicate the $b$ coefficient from Eq. 1.

The weight-at-length relationship for lionfish in the central Mexican Caribbean was calculated with the allometric growth function:

$$
T W=a T L^{b}
$$

Where $a$ is the ponderal index and $b$ is the scaling exponent or allometric parameter. We linearized the equation using $\log _{10}$-transformation and estimated the coefficients using an Ordinary Least Squares Regression with a heteroskedastic-robust standard error correction (Zeileis, 2004). Coefficients were tested with a two-tailed Student's t-test, and the significance of the regression was corroborated with an F-test. Some of the reviewed studies (Table 1, Fig 1) inconsistently defined $a$ as either the ponderal index from Eq. 1 or the y-intercept from the linearized log-transformed equation. Other studies incorrectly reported parameters as mm-to-g conversions when they were in fact $\mathrm{cm}$-to-g conversions. We standardized each study by converting coefficients and report all parameters as TL $(\mathrm{mm})$ to TW $(\mathrm{g})$ conversions.

We obtained a total of 18 parameter pairs by combining length-weight parameters extracted from the literature and the additional pair calculated here (Table 1). Recall that the objective of this study is not to describe differences in the length-weight relationship between populations (which would require access to raw data), but rather to assess how ex situ parameter values influence the accuracy of weight estimates for lionfish, using the central Mexican Caribbean as a case study. Using each of the 18 parameter pairs, we estimated $T W$ from the $T L$ observations collected in the central Mexican Caribbean ( $\mathrm{n}=109$, with $T L$ ranging from $34 \mathrm{~mm}$ to $310 \mathrm{~mm}$ ) and divided predicted weights by known observed weights to obtain a simple measure of over- or underestimation. Difference in mean weight ratios were tested with an analysis of covariance (ANCOVA):

$$
R_{i, j}=\tilde{\mu}+\alpha_{j}+\beta T L_{i j}+e_{i j}
$$


Where $R_{i j}$ is the weight ratio for the $i$-th organism obtained with parameters from the $j$-th study, $\tilde{\mu}$ is a constant for all individuals, $a_{j}$ is the treatment effect (i.e., the difference induced by each study), $T L_{i j}$ is the covariate (i.e., Total Length) for the $i$-th subject in the $j$-th group with slope $\beta$, and $e_{i j}$ is the error term of the regression. Ratios were logit-transformed prior to analysis, and a post-hoc Tukey's test was used to identify groups where mean ratios did not differ. All analyses were performed in $\mathrm{R}$ version 3.5.2 (R Core Team, 2018). Raw data and code used in this work are available on github at github.com/jcvdav/lionfish_biometry.

Table 1. Summary of 18 allometric growth parameters available for lionfish in the invaded range from peer-reviewed literature and this study. All parameters have been adjusted to convert from millimeters to grams. $\mathrm{n}=$ Sample size, Sex specifies whether data was presented for Females (F), Males (M), or both sexes combined $(\mathrm{B}), \mathrm{a}=$ scaling parameter (presented in $\left.\times 10^{-5}\right), \mathrm{b}=$ exponent.

\begin{tabular}{llllrll}
\hline Region & Sex & $\mathrm{n}$ & $\mathrm{a}$ & $\mathrm{b}$ & $R^{2}$ & Reference \\
\hline Western Atlantic & $\mathrm{B}$ & 774 & 2.90 & 2.89 & - & Barbour et al., 2011 \\
Western Atlantic & $\mathrm{B}$ & - & 0.25 & 3.29 & - & Darling et al., 2011 \\
GoM & $\mathrm{B}$ & 934 & 0.21 & 3.34 & 0.98 & Dahl \& Patterson, 2014 \\
GoM & $\mathrm{B}$ & 472 & 0.29 & 3.30 & 0.95 & Aguilar-Perera \& Quijano-Puerto, 2016 \\
GoM & $\mathrm{F}$ & 67 & 0.12 & 3.47 & 0.95 & Aguilar-Perera \& Quijano-Puerto, 2016 \\
GoM & $\mathrm{M}$ & 59 & 0.42 & 3.23 & 0.95 & Aguilar-Perera \& Quijano-Puerto, 2016 \\
GoM & $\mathrm{B}$ & 582 & 0.14 & 3.43 & 0.99 & Fogg et al., 2013 \\
GoM & $\mathrm{M}$ & 119 & 0.27 & 3.31 & 0.97 & Fogg et al., 2013 \\
GoM & $\mathrm{F}$ & 115 & 0.68 & 3.14 & 0.94 & Fogg et al., 2013 \\
Caribbean & $\mathrm{B}$ & 458 & 3.60 & 2.81 & - & Sandel et al., 2015 \\
Caribbean & $\mathrm{B}$ & 419 & 2.80 & 2.85 & 0.87 & Chin et al., 2016 \\
Caribbean & $\mathrm{B}$ & 1450 & 2.30 & 2.89 & 0.92 & de Leon et al., 2013 \\
Caribbean & $\mathrm{B}$ & 1887 & 0.30 & 3.24 & 0.97 & Edwards et al., 2014 \\
Caribbean & $\mathrm{B}$ & 2143 & 0.52 & 3.18 & 0.99 & Sabido-Itza et al., 2016 \\
Caribbean & $\mathrm{B}$ & 227 & 0.80 & 3.11 & 0.96 & Toledo-Hernández et al., 2014 \\
Caribbean & $\mathrm{B}$ & 449 & 0.23 & 3.25 & 0.97 & Sabido-Itza et al., 2016b \\
Caribbean & $\mathrm{B}$ & 368 & 0.32 & 3.19 & 0.98 & Sabido-Itza et al., 2016b \\
Caribbean & $\mathrm{B}$ & 109 & 0.32 & 3.23 & 0.98 & This study \\
\hline
\end{tabular}




\section{RESULTS}

The length-weight relationship for organisms from the central Mexican Caribbean (Fig 2) resulted in coefficient values of $a=3.205 \times 10^{-6}$ and $b=3.235\left(R^{2}=0.977, F_{1.107}=6928.67 ; p<0.001\right)$. The allometric factor $(b)$ was significantly different from $b=3\left(t_{107}=6.04 ; p<0.001\right)$, corroborating that lionfish present allometric growth. The length-weight coefficients estimated here were within the range identified by studies from other regions (Fig 3, Table 1).

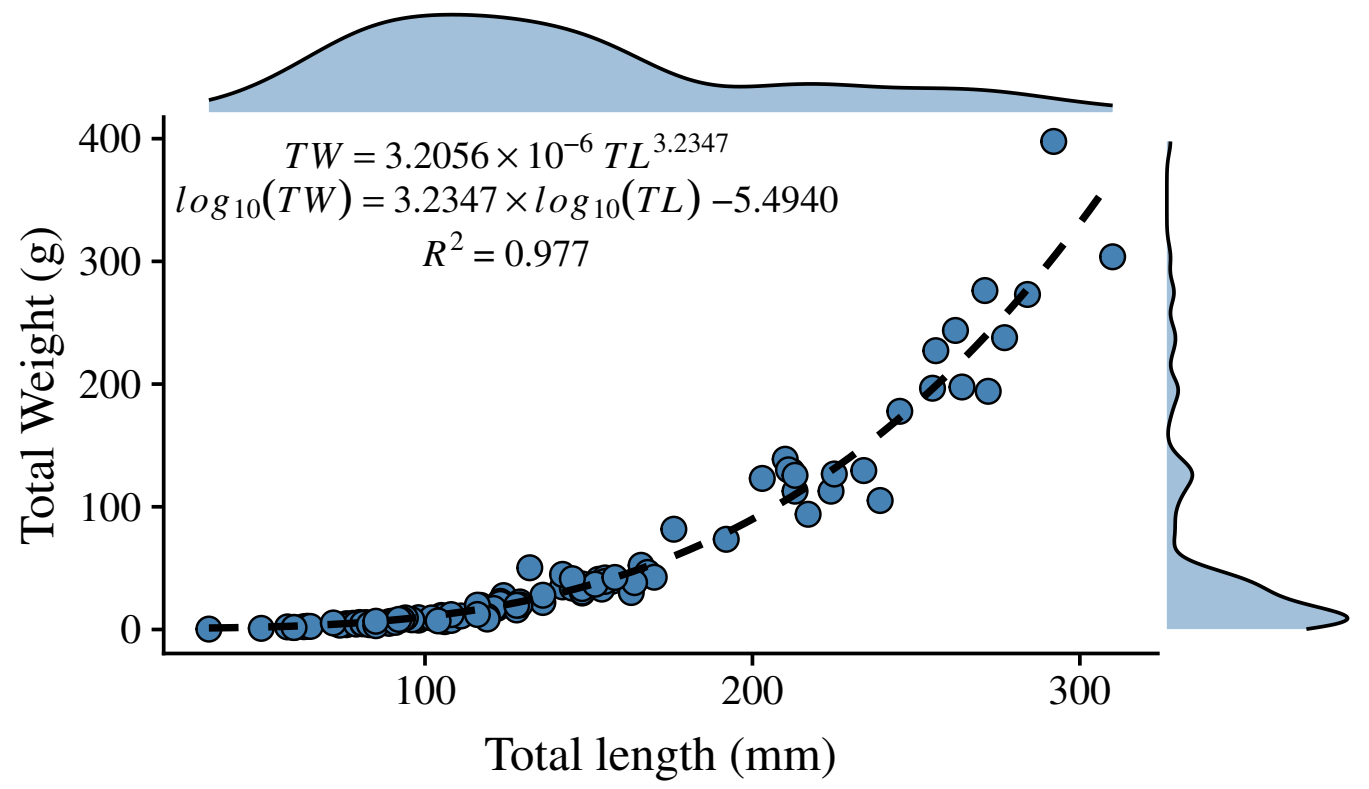

Figure 2. Length-weight relationship for 109 lionfish sampled in the central Mexican Caribbean. Points indicate samples, dashed black line indicates curve of best fit, marginal plots represent the density distribution of each variable.

ANCOVA results revealed significant differences in our predicted weight ratios for the central Mexican Caribbean when using each of the different pairs of parameters $\left(F_{17,1943}=24.96 ; p<0.001 ;\right.$ Fig 4$)$. For example, the actual observed weights of the 109 lionfish from the Central Mexican Caribbean had a mean $\pm \mathrm{SD}$ of $52.56 \pm 76.58 \mathrm{~g}$. However, if we used allometric parameter values from Banco Chinchorro in the Caribbean to predict weights from our observed length observations, we estimated a mean $\pm \mathrm{SD}$ of 40.37 \pm 58.74 g (Sabido-Itzá et al., 2016). If we similarly used parameter values from North Carolina in the Western Atlantic to estimate lionfish weights in the Central Mexican Caribbean, we found a mean \pm SD of $73.76 \pm 96.11 \mathrm{~g}$ (Barbour et al., 2011). Weights predicted from these extreme parameters correspond to mean predicted-to-observed weight ratios of $0.80 \pm 0.19$ and $1.76 \pm 0.50$ (mean $\pm \mathrm{SD}$ ), respectively. Furthermore, largest errors for individual organisms collected in the central Mexican Caribbean resulted in ratios of 0.36 and 3.51 (i.e., the tails of each violin in Fig 4). If we examined biomass (i.e., summing across all 109 organisms) instead of mean ratios, total biomass estimates were $76.2 \%(4,363.53 \mathrm{~g})$ and $140 \%$ $(8,039.96 \mathrm{~g})$ of true observed biomass $(5,729.34 \mathrm{~g})$. Parameters for this study estimate total biomass at 98\% of observed biomass (Fig 5). These misestimates come from the two most extreme sets of parameters, but results varied consistently across locations (Figs 4 and 5). Overall, the use of ex situ parameters led to significantly erroneous estimates of individual weight and total biomass for lionfish.

Tukey's post-hoc test showed that weight ratios for the central Mexican Caribbean differeed from those obtained with parameters from the Western Atlantic, and most sites in the Caribbean and the Gulf of Mexico (Tukey's HSD $p>0.05$ ). The only sites where weight ratios did not differ from the central Mexican Caribbean were Little Cayman (Edwards et al., 2014), Bahamas (Darling et al., 2011), and the Northern Gulf of Mexico (Dahl and Patterson (2014); Tukey's HSD $p>0.05$ ). All weight estimates using parameters from the Gulf of Mexico and Western Atlantic were higher than observed values, and only parameters from the Caribbean produced weights smaller than observed (Fig 4). The regional average ( \pm $\mathrm{SD}$ ) of predicted-to-observed weight ratios from these three regions were $1.24 \pm 0.309,1.41 \pm 0.523$, 
and $1.20 \pm 0.423$ for the Gulf of Mexico, Western Atlantic, and Caribbean, respectively. This suggests that the smallest errors are observed when using parameters from other locations in the Caribbean.

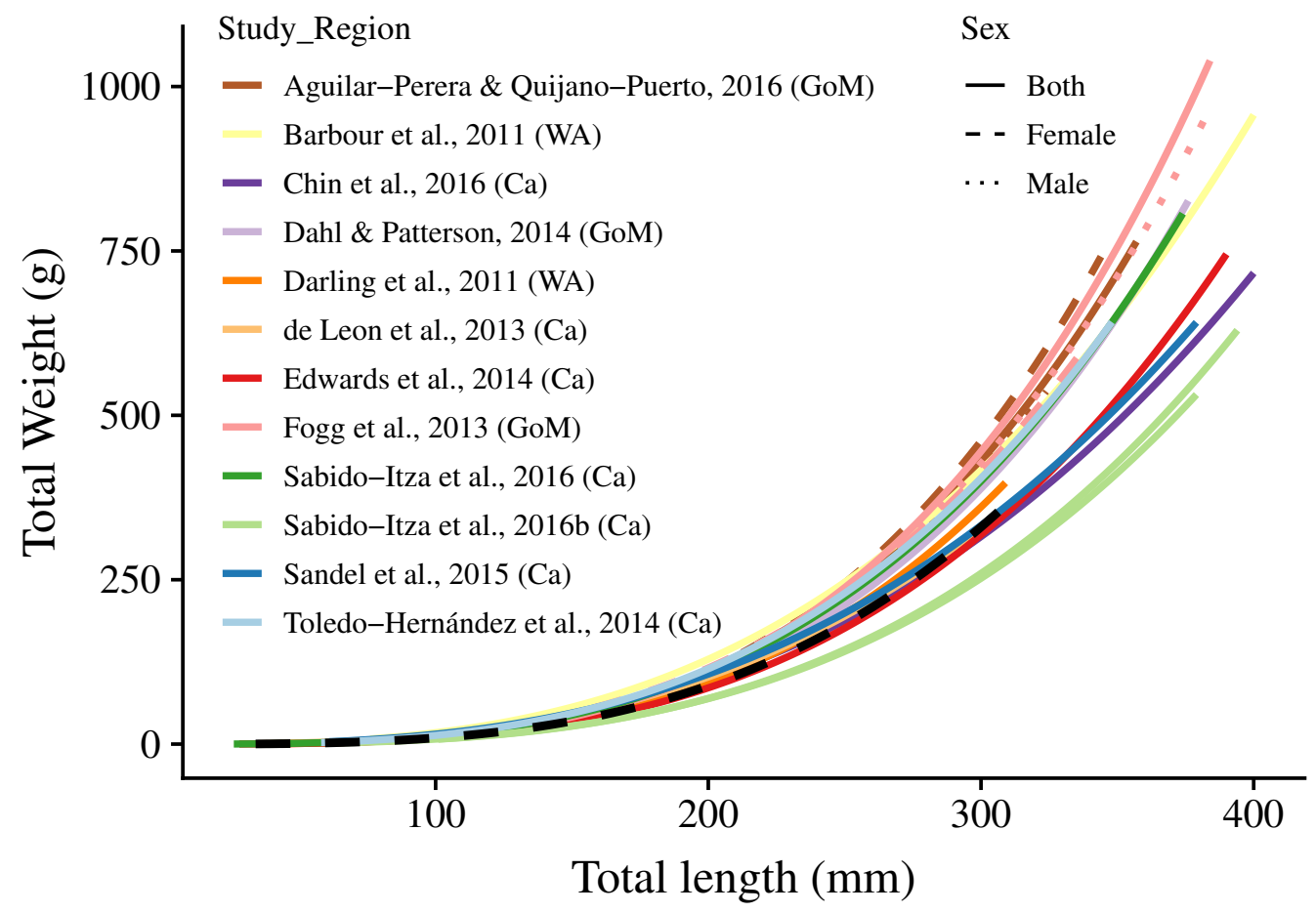

Figure 3. Length-weight relationships $(n=18)$ for 12 studies and this study. The curves are shown for the range of lengths reported in each study (See Supplementary Table 2); when ranges were not present, we use the ones found in this study $(34 \mathrm{~mm}-310 \mathrm{~mm})$. Colors indicate studies from which the parameters were extracted. Dotted, dashed, and solid lines show models for males, females, and combined sexes, respectively. Letters in parentheses indicate if the study comes from the Gulf of Mexico (GoM), Western Atlantic (WA), or Caribbean (Ca). The dashed black line represents the relationship estimated in this study. There are two solid green lines for Sabido-Itza et al, 2016b, one for each of the two sites for which they report parameters. A log-log version of this figure is presented in Figure S1. 


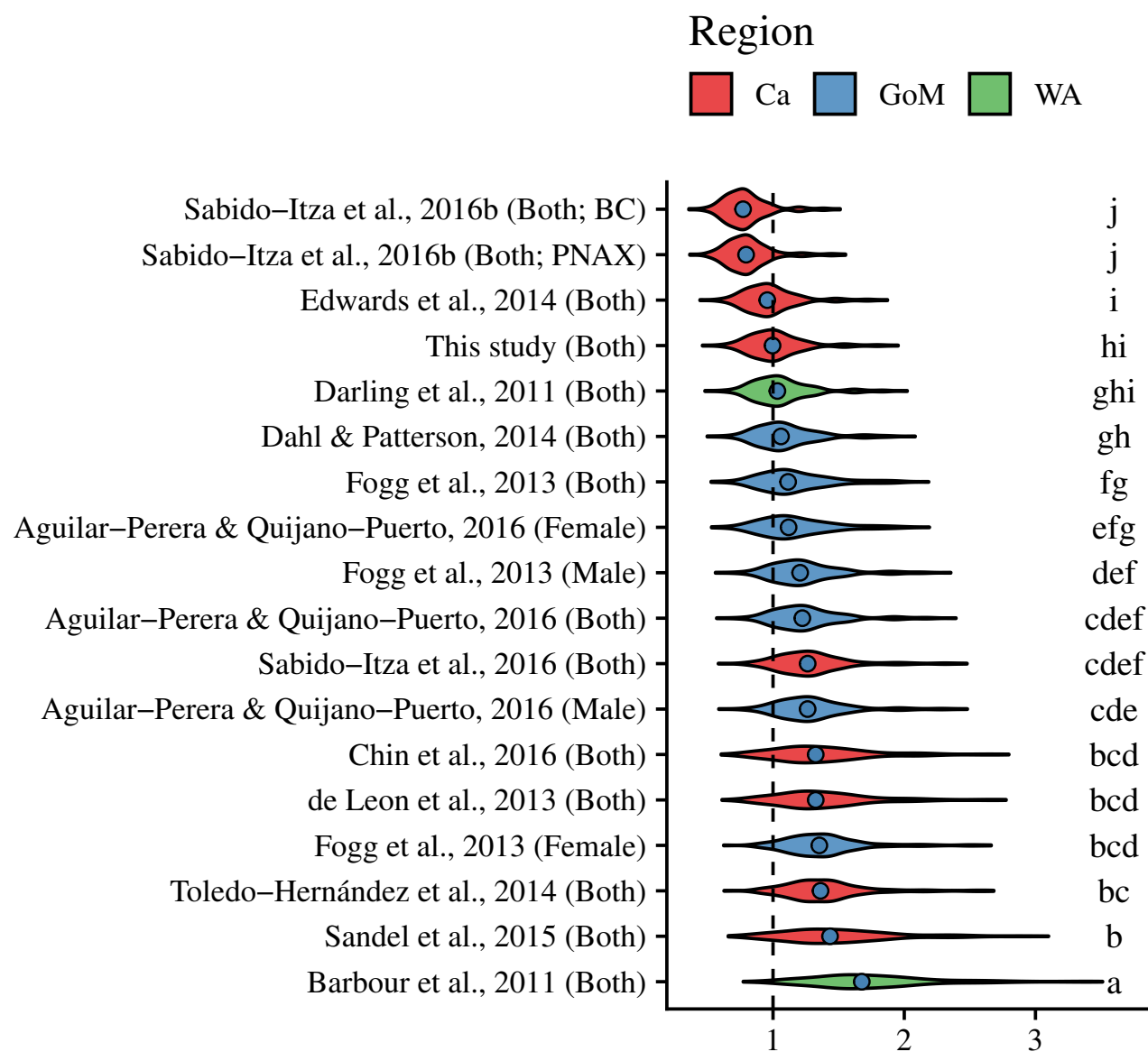

Weight ratio (Predicted/Observed)

Figure 4. Violin plot of predicted-to-observed weight ratios when applying each of 18 different pairs of allometric parameters to the 109 lionfish collected in the central Mexican Caribbean. Sex is indicated in parentheses. Blue circles indicate median values and like letters indicate values that do not differ significantly. For Sabido-Itza et al, 2016b, BC and PNAX make reference to Banco Chinchorro and Parque Nacional Arrecifes de Xcalak, two sites for which they report parameters. 


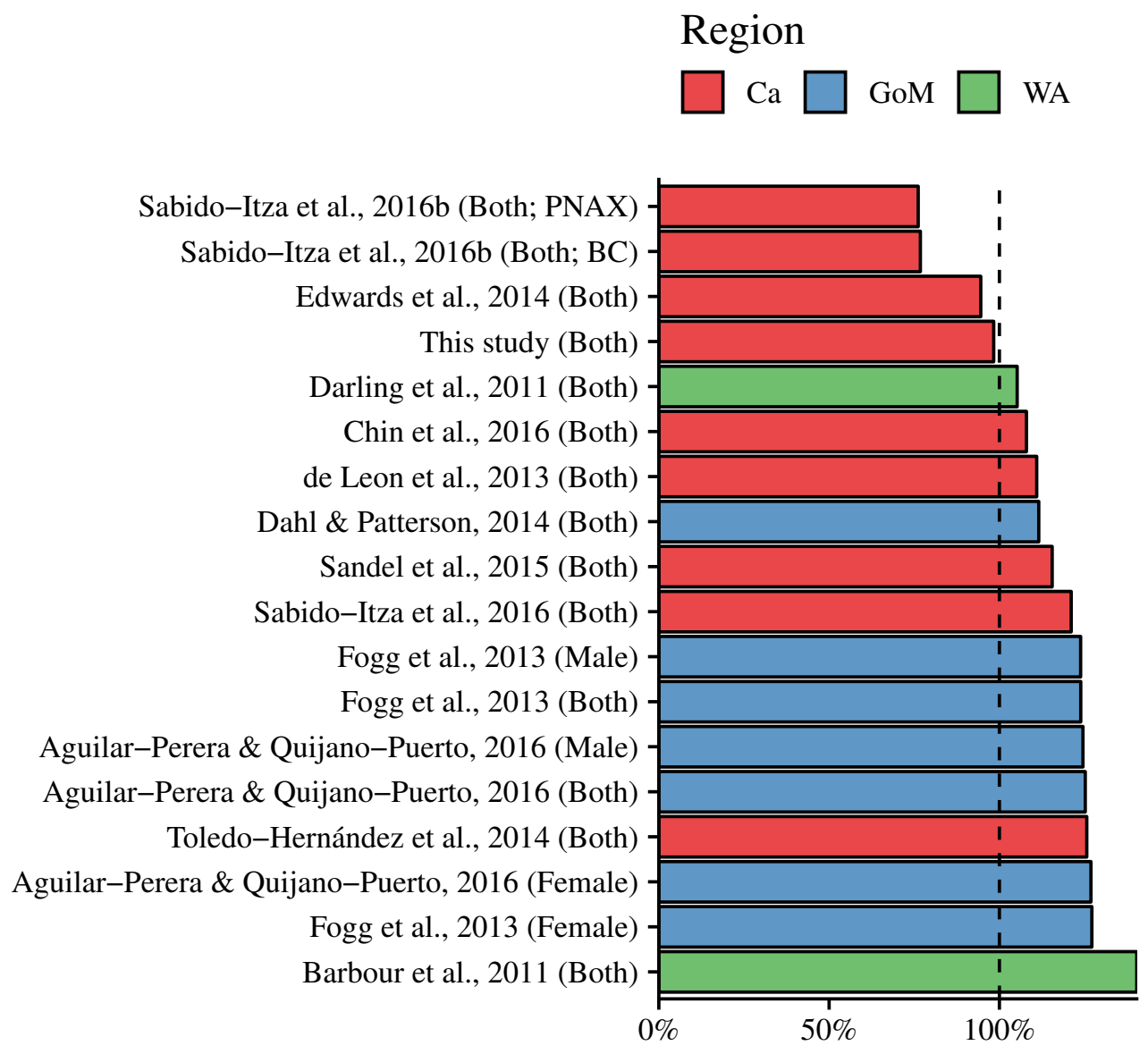

Total biomass relative to observed

Figure 5. Estimated total biomas relative to observed biomass (5,729.34 g) for 18 pairs of allometric parameters. Sex is indicated in parentheses. For Sabido-Itza et al, 2016b, BC and PNAX make reference to Banco Chinchorro and Parque Nacional Arrecifes de Xcalak, two sites for which they report parameters. 


\section{DISCUSSION}

Our results suggest that lionfish exhibit highly variable, spatially heterogeneous allometric relationships across their invaded range, and that this variation is relevant for managing invasions. Moreover, we show that the use of ex situ parameter values may lead to highly biased weight and total biomass estimates. Our comparison of observed weights to those predicted with locally-informed parameters and ex situ parameters showed that weight of an individual lionfish can be overestimated by more than threefold, highlighting the need to use local information. Here we discuss the implications of our findings, possible shortcommings in our analyses, and highlight potential future research directions.

Differences in length-weight relationships have traditionally been highlighted as potential pitfalls to fishery management. For example, Wilson et al. (2012) showed that small-scale variations in length-at-age and fishing mortality in other Scorpaeniformes translate to differential landings, effort, and catch per unit effort in the live fish fishery of California, and that these differences must be taken into account in management plans. The lionfish case poses the opposite scenario, where the manager desires to eradicate the species. To accurately gauge both the effectiveness of lionfish removal efforts and the resources needed to successfully manage an invasion, we must acknowledge and understand regional biological differences in important variables such as allometric growth parameters.

We detected substantial differences in weight-at-length between organisms from the Caribbean, Gulf of Mexico, and Western Atlantic. Groupings of predicted-to-observed weight ratios identified in our post hoc testing aligned with the spatial distribution of the examined studies, suggesting that these differences may be mediated by space. These regional allometric differences mirror similar patterns in length-at-age of lionfish across both their invaded and native regions (Pusack et al., 2016). Variation may be driven by genetics or by organisms' exposure to distinct environmental conditions. For example, Betancur-R et al. (2011) used mitochondrial DNA to demonstrate the existence of two distinct population groups, identified as the "Caribbean group" and "Northern Group", and Fogg et al. (2015) alternatively suggested that length-at-age differences may be driven by the environment.

One might be inclined to attribute all variation in the lionfish length-weight relationship to the spatial origin of these parameters. However, samples from the 12 studies included here were not only collected in different locations, but also at different points in time and across different depth and size ranges (See Supplementary Table 2 for an extended version of Table 1). The magnitude of the bias discovered in this study and our lack of understanding the sources driving spatial variation for lionfish highlights the need to simultaneously collect length-weight information across the invaded range to test for spatially-induced patterns and to link these findings to previously suggested environmental and genetic structures. Such an endeavor would provide insight into lionfish biology and better inform management. However, while we could not evaluate how these factors influenced length-weight estimates from previous studies without raw data, we still show that a lack of locally-calculated parameters can induce significant bias when calculating weight from length observations. We demonstrate the importance of using in situ parameters to obtain accurate weight estimates regardless of the underlying mechanisms driving variation between populations.

Applying parameter estimates to lengths outside the range of lengths originally used to estimate the parameters may also induce error. Our smallest observed organism was $34 \mathrm{~mm}$ in $T L$, and only two studies estimated parametrs with smaller organisms (Edwards et al., 2014; Sabido-Itza et al., 2016). By contrast, our largest organism had a $T L$ of $310 \mathrm{~mm}$, which is well within the range of all other studies (the next smallest maximum length was $325 \mathrm{~mm}$; See Supplementary Table 2). Due to the power function describing the allometric relationship (i.e., Eq. 1), the error in weight estimates is larger when extrapolation is done for lengths that are larger than the maximum length used to estimate the parameters. Our estimates are therefore conservative because we only used parameter pairs from other studies to estimate weights for lionfish up to $310 \mathrm{~mm}$ in the Central Mexican Caribbean, well within the range of lengths for which other parameters were estimated.

\section{CONCLUSION}

The results presented here have key implications for management. For example, Edwards et al. (2014) simulated a lionfish culling program under two scenarios, one using length-at-age and length-to-weight parameters from North Carolina and one using parameters from Little Cayman. Their results show that using different parameters caused up to a four-year difference in the time required for the simulated 
lionfish population to recover to $90 \%$ of its initial biomass after removals ceased.

Here, we show that using one set of length-weight parameters versus another for a given length can result in more than a threefold under- or overestimation of total weight for individual fish, and that total biomass estimates may range between $76 \%$ and $140 \%$ of true observed biomass. These differences become especially important when allocating resources for lionfish removal programs, incentivizing lionfish fisheries as a source of alternative livelihoods, or estimating ecosystem impacts. Research efforts focused on invasive lionfish populations need to use parameters calculated for their region to the extent possible, or use different sets of parameters that provide appropriate upper and lower bounds in their results.

\section{ACKNOWLEDGEMENTS}

We thank Nils Van Der Haar and Michael Doodey from Dive Aventuras as well as Guillermo Lotz-Cador who provided help to collect samples. We are grateful for comments raised by the editor and two anonymous reviewers, which significantly increased the quality of this work.

\section{REFERENCES}

Aguilar-Perera, A. and Quijano-Puerto, L. (2016). Relations between fish length to weight, and otolith length and weight, of the lionfish pterois volitans in the parque nacional arrecife alacranes, southern gulf of mexico. Rev. biol. mar. oceanogr., 51(2):469-474.

Albins, M. and Hixon, M. (2008). Invasive indo-pacific lionfish pterois volitans reduce recruitment of atlantic coral-reef fishes. Mar. Ecol. Prog. Ser, 367:233-238.

Andradi-Brown, D. A., Grey, R., Hendrix, A., Hitchner, D., Hunt, C. L., Gress, E., Madej, K., Parry, R. L., Régnier-McKellar, C., Jones, O. P., a Arteaga, M., Izaguirre, A. P., Rogers, A. D., and Exton, D. A. (2017). Depth-dependent effects of culling-do mesophotic lionfish populations undermine current management? R Soc Open Sci, 4(5):170027.

Arias-Gonzalez, J. E., Gonzalez-Gandara, C., Luis Cabrera, J., and Christensen, V. (2011). Predicted impact of the invasive lionfish pterois volitans on the food web of a caribbean coral reef. Environ Res, 111(7):917-925.

Barbour, A., Montgomery, M., Adamson, A., Diaz-Ferguson, E., and Silliman, B. (2010). Mangrove use by the invasive lionfish pterois volitans. Mar. Ecol. Prog. Ser., 401:291-294.

Barbour, A. B., Allen, M. S., Frazer, T. K., and Sherman, K. D. (2011). Evaluating the potential efficacy of invasive lionfish (pterois volitans) removals. PLOS ONE, 6(5):e19666.

Betancur-R, R., Hines, A., Acero, A., Orti, G., Wilbur, A., and Freshwater, D. (2011). Reconstructing the lionfish invasion: insights into greater caribbean biogeography. J Biogeography, 38:1281-1293.

Chin, D. A., Aiken, K. A., and Buddo, D. (2016). Lionfish population density in discovery bay, jamaica. International Journal of Scientific \& Engineering Research, 7(12):1327 - 1331.

Claydon, J., Calosso, M., and Traiger, S. (2012). Progression of invasive lionfish in seagrass, mangrove and reef habitats. Mar. Ecol. Prog. Ser., 448:119-129.

Côté, I. M., Akins, L., Underwood, E., Curtis-Quick, J., and Green, S. J. (2014). Setting the record straight on invasive lionfish control: Culling works. PeerJ.

Dahl, K. A. and Patterson, W. F. (2014). Habitat-specific density and diet of rapidly expanding invasive red lionfish, pterois volitans, populations in the northern gulf of mexico. PLoS ONE, 9(8):e105852.

Darling, E. S., Green, S. J., O'Leary, J. K., and Côté, I. M. (2011). Indo-pacific lionfish are larger and more abundant on invaded reefs: a comparison of kenyan and bahamian lionfish populations. Biol Invasions, 13(9):2045-2051.

de Leon, R., Vane, K., Bertuol, P., Chamberland, V. C., Simal, F., Imms, E., and Vermeij, M. J. A. (2013). Effectiveness of lionfish removal efforts in the southern caribbean. Endanger Species Res, 22(2):175-182.

Edwards, M. A., Frazer, T. K., and Jacoby, C. A. (2014). Age and growth of invasive lionfish (pterois spp.) in the caribbean sea, with implications for management. BMS, 90(4):953-966.

Fishelson, L. (1997). Experiments and observations on food consumption, growth and starvation in dendrochirus brachypterus and pterois volitans (pteroinae, scorpaenidae). Environmental Biology of Fishes, 50(4):391-403. 
Fogg, A. Q., Evans, J. T., Ingram JR, G. W., Peterson, M. S., and Brown-Peterson, N. J. (2015). Comparing age and growth patterns of invasive lionfish among three ecoregions of the northern gulf of mexico. In GCFI, G. and Institute, C. F., editors, Proceedings of the 68 th Gulf and Caribbean Fisheries Institute, Panama City. Gulf and Caribbean Fisheries Institute.

Fogg, A. Q., Hoffmayer, E. R., Driggers, W. B., Campbell, M. D., Pellegrin, G. J., and Stein, W. (2013). Distribution and length frequency of invasive lionfish (pterois sp.) in the northern gulf of mexico. GCR, 25.

Green, S. J., Akins, J. L., Maljković, A., and Côté, I. M. (2012). Invasive lionfish drive atlantic coral reef fish declines. PLoS ONE, 7(3):e32596.

Gress, E., Andradi-Brown, D. A., Woodall, L., Schofield, P. J., Stanley, K., and Rogers, A. D. (2017). Lionfish (pterois spp.) invade the upper-bathyal zone in the western atlantic. PeerJ, 5:e3683.

Guan, W., Cao, J., Chen, Y., and Cieri, M. (2013). Impacts of population and fishery spatial structures on fishery stock assessment. Can. J. Fish. Aquat. Sci., 70(8):1178-1189.

Gunderson, D. R., Parma, A. M., Hilborn, R., Cope, J. M., Fluharty, D. L., Miller, M. L., Vetter, R. D., Heppell, S. S., and Greene, H. G. (2008). The challenge of managing nearshore rocky reef resources. Fisheries, 33(4):172-179.

Hackerott, S., Valdivia, A., Cox, C. E., Silbiger, N. J., and Bruno, J. F. (2017). Invasive lionfish had no measurable effect on prey fish community structure across the belizean barrier reef. PeerJ, 5:e3270.

Hixon, M., Green, S., Albins, M., Akins, J., and Morris, J. (2016). Lionfish: a major marine invasion. Mar. Ecol. Prog. Ser., 558:161-165.

Hutchinson, W. F. (2008). The dangers of ignoring stock complexity in fishery management: the case of the north sea cod. Biol Lett, 4(6):693-695.

Johnson, E. G. and Swenarton, M. K. (2016). Age, growth and population structure of invasive lionfish (pterois volitans/miles) in northeast florida using a length-based, age-structured population model. PeerJ, 4:e2730.

Johnston, M. and Purkis, S. (2015). A coordinated and sustained international strategy is required to turn the tide on the atlantic lionfish invasion. Mar. Ecol. Prog. Ser., 533:219-235.

Jud, Z., Layman, C., Lee, J., and Arrington, D. (2011). Recent invasion of a florida (usa) estuarine system by lionfish pterois volitans / p. miles. Aquat. Biol., 13(1):21-26.

Jud, Z. R. and Layman, C. A. (2012). Site fidelity and movement patterns of invasive lionfish, pterois spp., in a florida estuary. Journal of Experimental Marine Biology and Ecology, 414-415:69-74.

Kochzius, M. and Blohm, D. (2005). Genetic population structure of the lionfish pterois miles (scorpaenidae, pteroinae) in the gulf of aqaba and northern red sea. Gene, 347(2):295-301.

Morris, J. A., Shertzer, K. W., and Rice, J. A. (2011). A stage-based matrix population model of invasive lionfish with implications for control. Biol Invasions, 13(1):7-12.

Muñoz, R., Currin, C., and Whitfield, P. (2011). Diet of invasive lionfish on hard bottom reefs of the southeast usa: insights from stomach contents and stable isotopes. Mar. Ecol. Prog. Ser., 432:181-193.

Peake, J., Bogdanoff, A. K., Layman, C. A., Castillo, B., Reale-Munroe, K., Chapman, J., Dahl, K., Patterson III, W. F., Eddy, C., Ellis, R. D., Faletti, M., Higgs, N., Johnston, M. A., Muñoz, R. C., Sandel, V., Villaseñor-Derbez, J. C., and Morris, J. A. (2018). Feeding ecology of invasive lionfish (pterois volitans and pterois miles) in the temperate and tropical western atlantic. Biol Invasions.

Pusack, T. J., Benkwitt, C. E., Cure, K., and Kindinger, T. L. (2016). Invasive red lionfish (pterois volitans) grow faster in the atlantic ocean than in their native pacific range. Environ. Biol. Fishes, 99(6-7):571-579.

R Core Team (2018). R: A Language and Environment for Statistical Computing. R Foundation for Statistical Computing, Vienna, Austria.

Rocha, L. A., Rocha, C. R., Baldwin, C. C., Weigt, L. A., and McField, M. (2015). Invasive lionfish preying on critically endangered reef fish. Coral Reefs, 34(3):803-806.

Sabido-Itzá, M., Aguilar-Perera, A., and Medina-Quej, A. (2016). Length-weight and length-length relations, and relative condition factor of red lionfish, pterois volitans (actinopterygii: Scorpaeniformes: Scorpaenidae), from two natural protected areas in the mexican caribbean. Acta Icth et Piscat, 46(4):279-285.

Sabido-Itza, M., Medina-Quej, A., De Jesus-Navarrete, A., Gomez-Poot, J., and Garcia-Rivas, M. (2016). Uso de la estructura de tallas como evidencia del establecimiento poblacional del pez le?n pterois volitans (scorpaeniformes: Scorpaenidae) en el sur del caribe mexicano. RBT, 64(1):353. 
Sandel, V., Martínez-Fernández, D., Wangpraseurt, D., and Sierra, L. (2015). Ecology and management of the invasive lionfish pterois volitans/miles complex (perciformes: Scorpaenidae) in southern costa rica. Rev Biol Trop, 63(1):213-221.

Schofield, P. (2009). Geographic extent and chronology of the invasion of non-native lionfish (pterois volitans [linnaeus 1758] and p. miles [bennett 1828]) in the western north atlantic and caribbean sea. $A I, 4(3): 473-479$.

Schofield, P. (2010). Update on geographic spread of invasive lionfishes (pterois volitans [linnaeus, 1758] and p. miles [bennett, 1828]) in the western north atlantic ocean, caribbean sea and gulf of mexico. $A I$, 5:S117-S122.

Toledo-Hernández, C. (2014). Population ecology and genetics of the invasive lionfish in puerto rico. AI, 9(2):227-237.

Usseglio, P., Selwyn, J. D., Downey-Wall, A. M., and Hogan, J. D. (2017). Effectiveness of removals of the invasive lionfish: how many dives are needed to deplete a reef? PeerJ, 5:e3043.

Villaseñor-Derbez, J. C. and Herrera-Pérez, R. (2014). Brief description of prey selectivity and ontogenetic changes in the diet of the invasive lionfish pterois volitans (actinopterygii, scorpaenidae) in the mexican caribbean. PANAMJAS, 9(2):131-135.

Wilson, J. R., Kay, M. C., Colgate, J., Qi, R., and Lenihan, H. S. (2012). Small-scale spatial variation in population dynamics and fishermen response in a coastal marine fishery. PLOS ONE, 7(12):e52837.

Zeileis, A. (2004). Econometric computing with hc and hac covariance matrix estimators. J Stat Softw, 11(10). 